\title{
Ideas about altruism and selfishness in students with different levels of empathy
}

\author{
Irina Kashirskaya ${ }^{1, *}$ \\ ${ }^{1}$ Southern Federal University (SFEDU), 105/42 Bolshaya Sadovaya Str., Rostov-on-Don \\ 344006, Russia
}

\begin{abstract}
An empirical study is devoted to the study of ideas about altruism and selfishness of students with different levels of empathy. The sociopsychological phenomena of altruism and egoism have different causes and manifestations, as well as different external and internal factors that strengthen or restrain their manifestations. One of the main factors is the influence of a person's personal characteristics. The study examines the relationship of ideas about altruism and selfishness with the level of empathy of students. Empathy was studied using a diagnostic technique, and representations were studied using a content analysis method. The study compared three groups of students: those with high levels of empathy, those with medium levels, and those with low levels of empathy. It is shown that students have an ambiguous attitude to altruism and selfishness, highlighting both the pros and cons of helping behavior. Differences were identified in the following categories: positive and negative associations associated with the words "altruism" and "egoism"; ideas about the negative consequences of altruism and ideas about the positive consequences of egoism; ideas about gender influence on altruism and selfishness of the individual; ideas about personal determinants of altruism and selfishness; students ' ideas about the expression of altruism and selfishness in themselves. It is proved that students with different levels of empathy have differences in the features of ideas about altruism and selfishness.
\end{abstract}

\section{Introduction}

Altruism is not only a psychological phenomenon, but perhaps more of a social phenomenon. The concept of " altruism "as opposed to the concept of" egoism " is the subject of research and discussion in the philosophical, sociological and psychological Sciences, and there is no single point of view either in the definition of the concept or in the understanding of its content until now. Since altruism is considered as one of the social representations, in everyday consciousness the understanding of its essence corresponds to the realities of today. Despite the fact that most people understand altruism as selfless helping behavior towards other people or society as a whole, sometimes contrary to their own interests, there are many nuances and contradictions in the understanding of this socio-psychological phenomenon. In today's dynamically changing society, social ideas about altruism and egoism are also undergoing changes, so it is important to study the attitude of modern youth to altruistic

\footnotetext{
* Corresponding author: k_irinak@mail.ru
} 
manifestations, to prosocial behavior or to individualistic attitudes and, accordingly, to the egoistic behavior model.

Within the framework of different disciplinary approaches, preference is given either to the evolutionary, genetic interpretation of the origin and development of altruism [1,2,3], or to the emphasis on the social aspect when explaining the selfless mutual assistance of strangers and understanding altruism as the opposite of egoism, but not contradictory, but complementary phenomena [4].

The correlation of motives in altruistic or egoistic behavior in situations of social interaction is complex and interdependent. A person can help another person at the moment selflessly, not counting on a return service, but at the same time subconsciously focus on maintaining or establishing interpersonal relationships that will help meet any needs in the hypothetical future. Therefore, the ability to communicate positively in the community allows a person who commits altruistic acts to feel satisfied, without paying attention to the immediate benefits. Thus, prosocial behavior is based not only on altruistic, but also on egoistic motives. A person who helps another person counts on reciprocity, i.e. support, if not now, then in the future, if necessary, to satisfy their material or psychological needs [5]. This point of view is quite common, and theories are being developed that prove the dual motivation of prosocial behavior. In addition, active social interaction encourages altruistic behavior and limits egoistic behavior [6].

We assumed that modern boys and girls have an ambiguous attitude to altruism and selfishness and do not perceive them as phenomena of different modality, but are aware of both positive and negative aspects of both altruism and selfishness, which was confirmed in our study.

Recognizing the positive aspects of prosocial behavior that are pressing in everyday consciousness, students name the negative consequences of altruism. This correlates with the assumptions of Robert Houmant, who believes that selfless altruistic actions can create the image of a "victim" and thus provoke even criminal reactions of other people who want to abuse the trust of the helping person [7]. He even coined the term "risky altruism", suggesting that responsiveness, helping strangers can attract scammers and the altruist risks becoming a victim of dishonest and even dangerous responses. This view is shared by other authors who believe that certain behaviors attract criminals [8].

In this context, the question of moral choice is interesting, when a person can commit an altruistic act, or can evade it, without violating moral norms and therefore not look either in their own eyes or in the eyes of society as an egoist. This method of avoiding prosocial behavior is much easier than open forms of egoism [9].K. Wenzel, investigating the phenomenon of altruism as one of the values of modern society, indicates that it correlates with the individual value of self-expression [10]. As S. Schwartz proves in his cross-cultural research in modern society, individualistic values do not necessarily contradict prosocial behavior, but they can be combined with altruistic behavior [11].

In accordance with the purpose of this work, we are interested in research on the relationship between empathy and altruism. Effective empathy as active assistance to another person or group corresponds to altruistic behavior.

Empathy in the process of socialization of the individual goes through certain stages or stages of formation. During the newborn period, the child learns to respond emotionally to the presence of an adult, in preschool age, the processes of emotional infection and imitation are activated, and at this age, the beginnings of prosocial behavior are already observed. M. Shaffer, studying parenting styles, proved their connection with empathy and, accordingly, with antisocial and prosocial behavior. The lack of close emotional child-parent relationships, authoritarian as well as liberal parenting styles are favorable factors for manifestations of antisocial behavior in children and adolescents as a result of a low level of empathy development [12]. 
In adolescence and at the stage of maturity, the individual acquires and accumulates social experience, which makes it possible to show different forms of empathy. Thus, at each stage of age-related development, new features of empathy appear. At each age stage, new factors appear that determine the features of empathic manifestations in this period and new mechanisms of social interaction and social perception.

The formation of a new level of prosocial behavior (not only empathy, but also empathy as a more perfect form of empathy) in adolescence and adolescence is associated with the further development of the cognitive sphere, the emotional-volitional sphere, the expansion of the circle of communication, Dialogic communication, and the interiorization of moral and ethical concepts.

In adolescence and adolescence, when the motives of prosocial behavior are already recognized, and do not act only on a subconscious level, moral guidelines, views, principles and beliefs begin to play the role of a kind of motivators of behavior, and gradually value orientations increasingly influence the manifestations of altruistic behavior, the choice of actions and decisions in favor of another. I. M. Yusupov's research on the potential of empathic behavior of schoolchildren proves that the decrease in forms of empathy is in favor of an increase in forms of empathy, and this can be considered as altruistic behavior.

The emergence of friendship ties, a pair of communication enhances the interpersonal communication of teenagers and young men. The ability to empathize strengthens interpersonal relationships, social experience contributes to the further development of empathy.

If we assume that empathy as a personal neoplasm appears during puberty, then the adolescent period can be defined as a sensitive period for the development of empathy. In subsequent age periods, empathy itself will be a stimulator of prosocial behavior and altruism. The situational occurrence of empathic experiences can encourage a person to effectively help others and strengthen prosocial behavior, as well as block aggressive manifestations.

Analyzing the role of empathy in communication and professional activity of a teacherpsychologist, V. Dolgova and E. Melnik pay attention to the fact that empathy in various spheres of mental reflection has many forms and manifestations and acts as a regulator of interpersonal relations and as a motive for altruistic behavior [13].

Batson believes that empathy is one of the main factors in the formation of helping behavior. A person who is inclined to empathy and empathy is more ready to help in a specific situation than an individual with a low level of empathy $[14,15]$.

\section{Methods}

The aim of the study is to identify the features of ideas about altruism in students with different levels of empathy.

We suggested that students with different levels of empathy have differences in the features of ideas about altruism and selfishness in different content parameters.

The empirical study was conducted using the following diagnostic tools: 1. Questionnaire "the Idea of altruism-egoism", compiled by us; 2. Mini-essay "What is altruism and egoism"; 3. Method "Diagnostics of the level of empathy" by I. M. Yusupov. Frequency analysis was used for statistical processing

The study involved 80 students of the southern Federal University.

\section{Results}

Based on the diagnostic method, the level of empathy of students was revealed. 
Approximately half of the students participating in the study have an average level of empathy development (47\%). This indicator characterizes these students as people who are quite sensitive to the experiences of others. In interpersonal relationships, they are more rational, judging others by their actions, rather than by words and emotional expressions. When reading works of art and watching movies, they are more likely to follow the action than the experiences of the characters. They have a limited repertoire of helping actions, do not particularly delve into the subtle nuances of emotions and feelings of the partner. Empathic responsiveness is situational and limited to a certain circle of people (primarily their immediate environment). When helping other people, they hope for social approval of their behavior by others.

Young men and women with a high level of empathy (24\%) are able to react emotionally to others, empathize, and participate. Such students are able not only to understand the behavior of a communication partner on a rational, but also on an intuitive level, even if there is a lack of initial information about them.

A third of today's young men and women have a low level of empathy (29\%), therefore, they either consider it inappropriate to show interest in the problems of people around them, or they do not know how to be emotionally responsive to others. Such students are most likely to use stereotypes of perception, do not know how to put themselves in the place of another.

To interpret the results of the questionnaire and mini-essay using content analysis, the following categories were identified:

1. Positive and negative associations associated with the words "altruism" and " selfishness»;

2. Negative consequences of altruistic behavior.

3. Positive consequences of selfish behavior.

4. Gender aspect of altruism and selfishness;

5. Personal determinants of altruism;

6. Personal determinants of selfishness.

7. self-Assessment of altruism and selfishness.

All respondents were divided into three groups: a) students with a high level of empathy, b) students with an average level, and C) students with a low level. We conducted a comparative analysis of the ideas about altruism and selfishness of students in these groups. The number of all subjects in one of the groups was taken as $100 \%$. Thus, the figures indicate the number of students in $\%$ of the total number included in this group.

1. Positive and negative associations associated with the words "altruism"and " selfishness".

The first criterion identified by experts for analysis concerns associations associated with the words altruism and selfishness. All such statements of students for each position, extracted from the answers to the questionnaire questions and from the texts of mini-essays, were taken as $100 \%$ in accordance with the level of empathy. Next, we calculated the number of positive and negative associations associated with the concept of "altruism" and, accordingly, the number of positive and negative associations associated with the concept of "egoism".

Among students with a high level of empathy, $86 \%$ of associations are positive, and only $14 \%$ are negative. In students with an average level of empathy, only a quarter of statements $(26 \%)$ are negative associations, the rest are positive associations. Students with low levels of empathy have a different picture. In this group, only $60 \%$ of statements are positive, and $40 \%$ are negative associations.

Thus, most students ' ideas about altruism are associated with positive associations, i.e. they are accompanied by positively colored emotional experiences. However, there are also 
negative associations, the largest number of such statements were found in students with a low level of empathy.

Examples of positive associations: "increases self-esteem, no sense of guilt that didn't help," "moral satisfaction", "you can count on reciprocal help", "admired", "strengthening friendship", "gratitude people", "respect", "new experience, new knowledge»,

Examples of negative associations: "loss of time", "guilt that I did something wrong", "fatigue", "a person begins to avoid communication because he feels obligated", "excessive responsibility", "you are being manipulated", "not doing your own business", "planned plans are collapsing", "money losses".

Students ' attitude to the concept of "egoism" is not so unambiguous as to the concept of "altruism". All students have positive associations with the word egoism, but in different amounts in comparison with altruism.

In students with a high level of empathy, one-third of statements are positive (28\%). Students with an average level of empathy have $42 \%$ of such statements. Students with a low level of empathy have even more positive associations associated with the word egoism than negative associations ( $54 \%$ and $46 \%$, respectively).

Examples of positive associations: "independence of decisions", "independence"," no failures"," no one owes anyone"," no responsibility for others"," personal freedom"," free time","monetary independence".

Examples of negative associations: "guilt", "the possibility of conflict", "resentment of people", "others will not help either", "envy", "greed".

2. Negative consequences of altruistic behavior.

We analyzed these negative consequences of altruistic behavior and identified the most common ones.

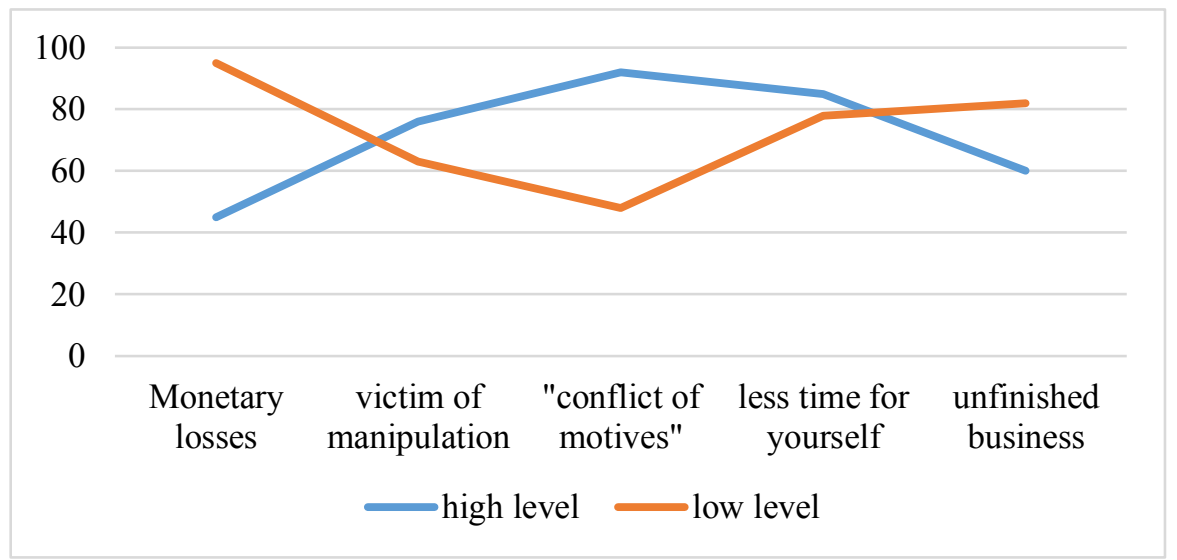

Fig. 1. Negative consequences of altruism in the perceptions of students with high and low levels of empathy.

Students with a high level of empathy most often call such negative consequences of altruism (in descending order):" conflict of motives "(to solve their own problems or others'), less time for themselves, the possibility of becoming a victim of manipulation, unfinished business, money losses.

Students with a low level of empathy most often call the following negative consequences of altruistic behavior (in descending order): monetary losses, unfinished business, less time for themselves, the possibility of becoming a victim of manipulation, "conflict of motives.

Thus, students with different levels of empathy have different assessments of the significance of negative consequences. All the students named the negative consequences of 
altruism, only in different cases, i.e. they believe that altruistic behavior can have negative sides.

3. Positive consequences of selfish behavior.

We analyzed these positive consequences of egoistic behavior and identified the most common ones.

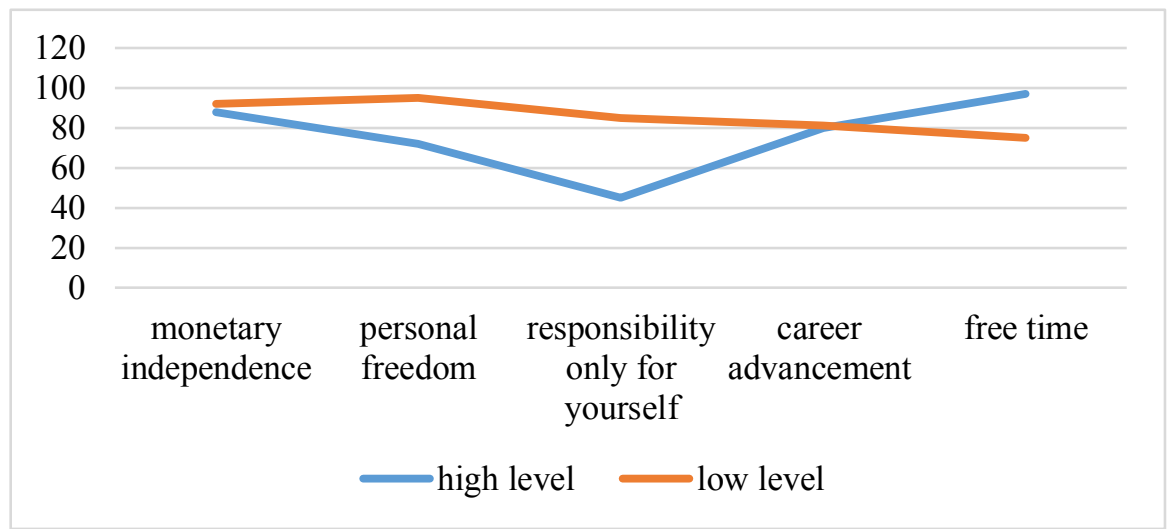

Fig. 2. Positive consequences of selfishness in the perceptions of students with high and low levels of empathy.

Students with a high level of empathy named the following positive consequences of egoistic behavior (in descending order): free time, monetary independence, career advancement (since their interests are above all), personal freedom, and responsibility only for themselves.

Students with a low level of empathy most often name such consequences as (in descending order): personal freedom, monetary independence, responsibility only for themselves, career advancement, free time.

Thus, there was a difference in the significance of consequences for students with different levels of empathy. All students, but to varying degrees, believe that selfishness is sometimes more profitable than altruism, since it has its positive aspects.

4. Gender aspect of altruism.

We analyzed the answers to the questionnaire question " who is more inclined to altruistic behavior, men or women?"

Students with a high level of empathy believe that there is not much difference between men and women in the tendency to altruistic behavior, in their opinion, women are only slightly more altruistic than men.

Students with low levels of empathy have the same ideas, but they, on the contrary, believe that men are slightly more altruistic than women.

Most students with an average level of empathy think that women are far superior to men in the desire to help others, i.e., they are much more likely to commit altruistic acts.

Thus, in the sample as a whole, in the views of the majority of students $(62.5 \%)$, women are more altruistic than men.

5. Personal determinants of altruism. 


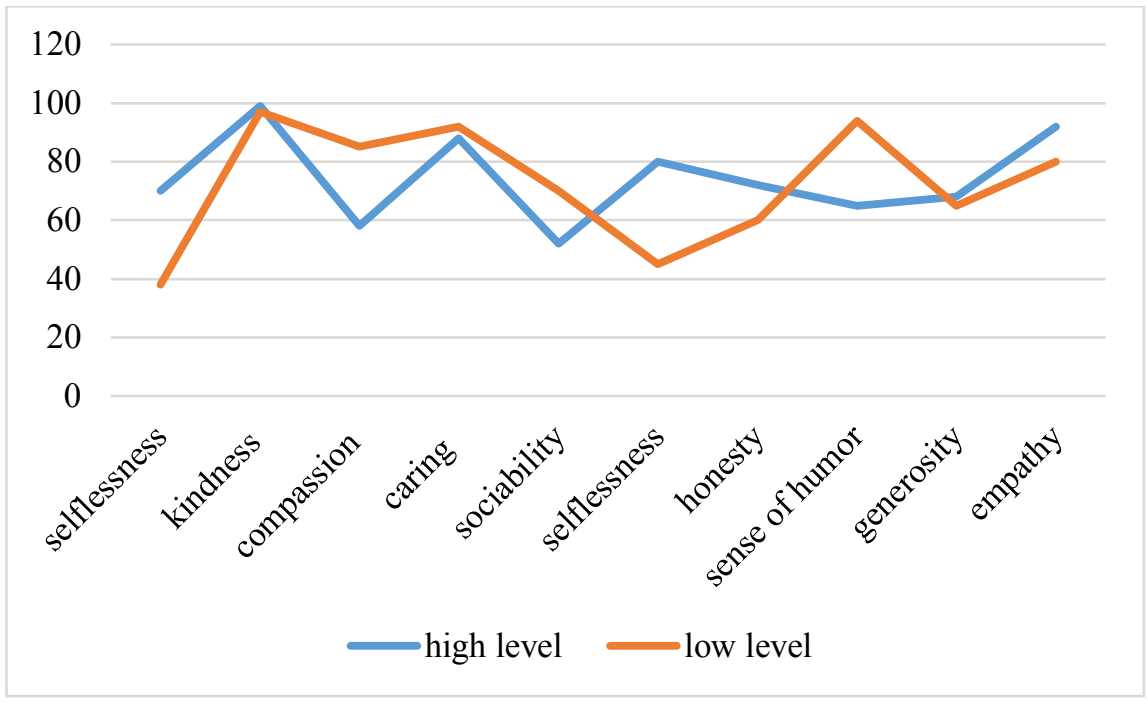

Fig. 3. Personal qualities associated with altruism in the views of students with high and low levels of empathy.

After analyzing the answers to the questionnaire question "What personal qualities are inherent in a person who is prone to altruistic behavior?» and the texts of the essays, we made a profile of the personality of the "altruist person" in the views of students with different levels of empathy.

Students with a high level of empathy most often associate the tendency to altruistic behavior with kindness, empathy, caring, selflessness and selflessness.

Students with low levels of empathy most often named such personal qualities as kindness, sense of duty, caring, compassion, and empathy.

The greatest differences were found in such qualities as selflessness, compassion, selflessness, and a sense of duty. Students with low levels of empathy do not really believe in selfless and selfless altruism.

6. Personal determinants of selfishness.

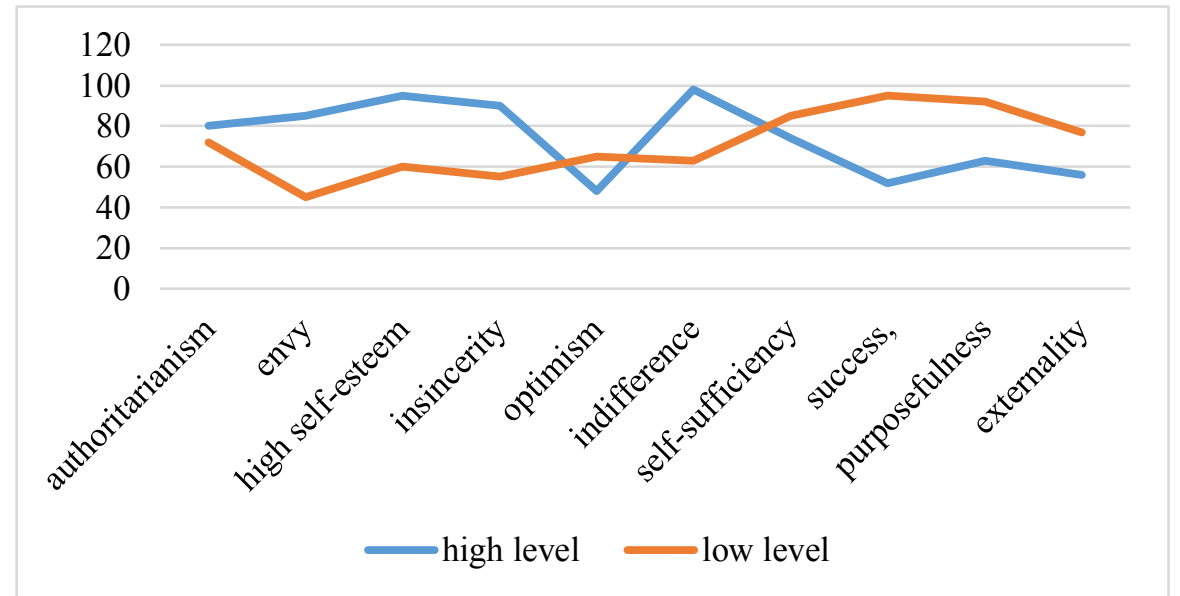

Fig. 4. Personal qualities associated with selfishness in the views of students with high and low levels of empathy. 
After analyzing the answers to the questionnaire question "What personal qualities are inherent in a person who is prone to selfish behavior?» and the texts of the essays, we made a profile of the personality of the "egoist person" in the views of students with different levels of empathy.

Students with a high level of empathy most often associate the tendency to selfish behavior with indifference, high self-esteem, insincerity, envy and authoritarianism.

Students with a low level of empathy most often named such personal qualities as success, purposefulness, self-sufficiency, externality and authoritarianism.

Thus, if the profile of an altruist consists only of positive qualities, then the profile of an egoist is much more complex and includes not only negative qualities, as one might assume, but also positive personal qualities. At the same time, students with a high level of empathy primarily call negative qualities, and students with a low level of empathy primarily call positive personal qualities.

7. Self-Assessment of altruism and selfishness.

We were interested in whether students consider themselves more altruistic or selfish.

It turned out that all students with a high level of empathy (100\%) consider themselves altruists. There are slightly more students with an average level of empathy who consider themselves altruists than students who consider themselves egoists $(55 \%$ and $45 \%$, respectively). It is very interesting that almost all students with a low level of empathy (83\%) recognized themselves as egoists. In General, the sample of altruistic and egoistic students was approximately equal in their own self-esteem, with a slight preponderance of students with an altruistic orientation ( $55 \%$ and $45 \%$, respectively).

\section{Discussion and Conclusions}

In the context of rapidly changing conditions and socializing factors of modern society, fundamental values, traditional ideas, social stereotypes, and moral guidelines are being transformed. Changes also concern social ideas about altruism and egoism, the need for prosocial behavior or individualistic attitudes, and there is a contradiction between altruistic and egoistic aspirations of people. On the one hand, the role of helping behavior increases due to the increasing number of those who need help and support (the disabled, the elderly, refugees, the unemployed, etc. On the other hand, competition for resources and the need for personal well-being lead to an increase in individualistic attitudes, an increase in indifference and selfishness, and a decrease in the desire to help. In our country, the volunteer movement is actively developing, but as our surveys have shown, first of all, young people choose such volunteer programs that bring them personal "benefits" (expanding social contacts, activating interpersonal communication, new experiences, new cognitive opportunities, improving language or professional skills, participating in creative projects, etc.). Very few choose to work in hospices, helping pensioners, caring for the homeless, etc. Modern young men and women, especially those belonging to such a social category as students, primarily respond to social transformations, often being their initiators.

The results of our research show that the ideas of altruism and selfishness of modern students do not have the same polarity of these concepts. Altruism and selfishness become independent variables and can combine and complement each other, while simultaneously motivating social behavior and relationships between people.

Our hypothesis that there are differences in the features of ideas about altruism among students with different levels of empathy was confirmed. These results allow us to conclude that the formation of empathy as a personal quality can contribute to the strengthening of altruistic attitudes and empathy becomes an effective motive for prosocial behavior. This makes it possible to set goals for the purposeful development of empathy in children and the development of educational programs for adolescents and adults. 


\section{References}

1. J. Crocker, A. Canevello, J. of personality a social psychology 3(95), 555-575 (2008)

2. C.K. De Dreu et al., Science 328, 1408-1411 (2010) DOI: 10.1126 /science.1189047

3. J-K. Choi, S. Bowles, Science 318, 636-640 (2007) DOI: 10.1126/science.1144237

4. J. Carlson, M. Horgan, Altruism, morality a social solidarity forum: A forum for scholarship a newsletter of the AMSS of ASA 1(3), 17-24 (2011)

5. L.E. Park, J.D. Troisi, J.K. Maner, J. of social a personal relationships 3(28), 315-335 (2011) DOI: 10.1177/0265407510382178

6. S.R. Brown, M.R. Brown, Psychological inquiry 1(17), 1-29 (2006) DOI: 10.1207/s15327965pli1701_01ISBN: 1047-840X

7. R.J. Homant, Criminal justice a behavior 11(37), 1195-1216 (2010) DOI: 10.1177/0093854810378841ISBN: 0093-8548

8. B.E. Turvey, W. Petherick, Forensic victimology: Examining violent crime victims in investigative and legal contexts (Elsevier, Boston (MA), 2009)

9. R. Teper, M. Inzlicht, Social psychological a. personality science 3(2), 284-288 (2011) DOI: $10.1177 / 1948550610389338$ ISBN: 1948-5506

10. C. Welzel, Journal of cross-cultural psychology 2(41), 152-174 (2010) DOI: $10.1177 / 0022022109354378$

11. S.H. Schwartz, Cultural value orientations: Nature and implications of national (State University-Higher School of Economics Press, Moscow, 2008)

12. M. Schaffer, Crime \& Delinquency 20, 1-14 (2009) DOI: 10.1177/0011128708321359ISBN: 0011-1287

13. V. Dolgova, E. Melnik, XXXVII international research and practice conference "Forms of social communication in the dynamics of human societ (2012)

14. C. Batson, Altruism in humans (Oxford University Press, New York, 2011)

15. C.D. Batson, N. Ahmad, European Journal of Social Psychology 31, 25-36 (2001) DOI: 10.1002/ejsp.26 ISBN: 1099-0992 